\title{
Localization of $\Delta^{5}-3 \beta$ - and $17 \beta$-hydroxysteroid dehydrogenase activity in the efferent ducts, epididymis and vas deferens of the rabbit, hamster and marmoset monkey
}

\author{
Asha Prakash and H. D. M. Moore \\ Institute of Zoology, Department of Reproduction, The Zoological Society of London, \\ Regent's Park, London NW1 4RY, U.K.
}

\begin{abstract}
Summary. The presence and distribution of $\Delta^{5}-3 \beta$-hydroxysteroid dehydrogenase ( $\Delta^{5}-3 \beta$-HSD: EC 1.1.1.51) and 17 $\beta$-hydroxysteroid dehydrogenase (17 $\beta$-HSD: EC 1.1.1.51) were studied histochemically in the excurrent ducts of the rabbit, hamster and marmoset monkey. Dehydroepiandrosterone (DHEA) and testosterone were used as substrates for $\Delta^{5}-3 \beta$-HSD and $17 \beta$-HSD respectively, while phenanthroline monohydrate was used to eliminate non-specific staining due to other tissue dehydrogenases. The rabbit possessed least enzyme activity, which was confined to tubules in the middle segment of the epididymis. Enzyme activity was demonstrable throughout the excurrent ducts of the hamster and marmoset, with maximal staining occurring in the middle segment of the epididymis in both species. The region of maximum activity of hydroxysteroid dehydrogenase is where spermatozoa first develop their fertilizing capacity.
\end{abstract}

\section{Introduction}

The epididymis is critically dependent on androgens from the circulation (Orgebin-Crist, Danzo \& Davies, 1975) and those derived from the testicular fluid (Fawcett \& Hoffer, 1979). In most mammalian species, testosterone and $5 \alpha$-dihydrotestosterone are the principal androgens required to maintain sperm maturation and viability, for a short time at least, after castration or hypophysectomy (Orgebin-Crist et al., 1975). Histochemical and biochemical studies in vitro suggest that steroids are metabolized and interconverted in the epididymal epithelium and possibly by spermatozoa (review: Hamilton, 1975); so a number of steroid metabolites may also be involved in epididymal function.

An important indication that the epididymal epithelial cells may synthesize steroids has been the demonstration in their cytoplasm of hydroxysteroid dehydrogenase activity. A major problem in studies using histochemical methods for localizing these enzymes is non-specific staining by other tissue dehydrogenases, such as alcohol dehydrogenase, which may be present. This makes it difficult to evaluate previous histochemical studies on the epididymis for which the controls have been inadequate (McGadey, Baillie \& Ferguson, 1966; Moniem, 1972; Killian \& Amann, 1974; Rastogi, Saxena \& Iela, 1976; Dinakar, Arora-Dinakar, Kumar, Talesara \& Prasad, 1977). The present investigation was designed to overcome this drawback while comparing the occurrence and regional distribution of $\Delta^{5}-3 \beta$ - and $17 \beta$-hydroxysteroid 
dehydrogenase (EC 1.1.1.51) ( $\Delta^{5}-3 \beta$-HSD and 17 -HSD) activity in the efferent ducts, epididymis and vas deferens of the rabbit, hamster and marmoset monkey.

\section{Materials and Methods}

The efferent ducts were removed intact from 4 adult male rabbits, 5 hamsters and 4 marmoset monkeys (Callithrix jacchus), killed by an intravenous injection of pentobarbitone sodium (Sagattal: May and Baker, Dagenham, Essex, U.K.). The ducts were immediately snap-frozen in isopentane at $-160^{\circ} \mathrm{C}$ and, before use, stored in liquid nitrogen. Longitudinal sections, $10 \mu \mathrm{m}$ thickness, of the whole excurrent duct of marmoset monkeys, or the proximal (efferent ducts to mid-corpus region of the epididymis) and distal (mid-corpus region of the epididymis to vas deferens) segments of the tracts of rabbits and hamsters were cut in a cryostat $\left(-18^{\circ} \mathrm{C}\right)$ and dry mounted onto coverslips. To localize steroid hydrogenases histochemically, sections were incubated in medium based on that used by Wattenburg (1958) and consisted of $2.46 \mathrm{~mm}$-nitro

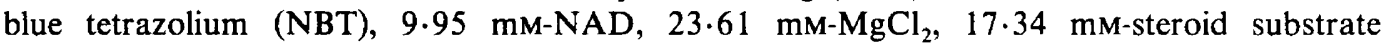
previously dissolved in dimethyl formamide (final concentration $0.13 \mathrm{M}$ ), and $0.12 \mathrm{M}$-Tris buffer at $\mathrm{pH} 7 \cdot 6-7 \cdot 8$. Dehydroepiandrosterone (DHEA: $\Delta^{5}$-androsten-3 $\beta$-ol-17-one) and testosterone

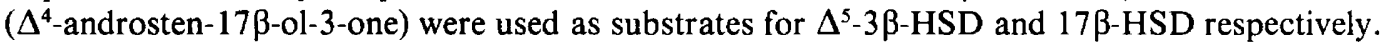
A preliminary study using ethanol as substrate indicated that alcohol dehydrogenase (EC 1.1.1.1) was present in the epididymal epithelium. Although this enzyme gave a more even pink stain with tetrazolium salts, as opposed to blue granular deposits formed by the action of steroid dehydrogenase, it was necessary to inhibit its activity to reduce non-specific staining. A 3-min pretreatment of sections in a saturated aqueous solution of $1: 10$ phenanthroline monohydrate (Sigma, Poole, Dorset, U.K.) in $0.12 \mathrm{M}$-Tris buffer, pH 7.6 was sufficient to inhibit the activity of alcohol dehydrogenase without appreciably reducing steroid dehydrogenase activity (Sigman, 1967). Sections, with and without phenanthroline treatment, were rinsed in Tris buffer, $\mathrm{pH} 7.6$ and then incubated at $37^{\circ} \mathrm{C}$ in $100 \%$ humidity for $2 \mathrm{~h}$ in medium containing substrate or in substrate-free control medium. After incubation, sections were rinsed in Tris buffer, fixed in $10 \%$ Tris-buffered formalin, washed in water and mounted in glycerol gel for examination and photography. Sections from the same blocks were stained with haematoxylin and eosin for histological examination.

Since diaphorase catalyses the transfer of $\mathrm{H}_{2}$ from NADH to the tetrazolium salt to form the coloured formazan, its presence in the excurrent ducts was histochemically tested in tissue sections by the method of Chayen, Bitensky, Butcher \& Poulter (1969). High activity of diaphorase was found throughout the tract in all three species indicating that steroid dehydrogenase activity was rate limiting in the formation of stain.

\section{Results}

The regions of the male excurrent ducts of the rabbit, hamster and marmoset monkey are defined in Text-fig. 1 and are based on morphological and ultrastructural observations (Glover \& Nicander, 1971; Nicander \& Plöen, 1979; Moore, 1981).

Phenanthroline, used in a preincubation step, markedly reduced the non-specific staining seen in control sections and in those treated with substrate. The following description therefore refers to observations made on phenanthroline-pretreated tissues.

\section{Rabbit}

Sections pretreated with phenanthroline and then incubated with steroid substrate displayed formazan reaction product only in tubules in the middle segment of the epididymis (Pl. 1, Figs 1, 

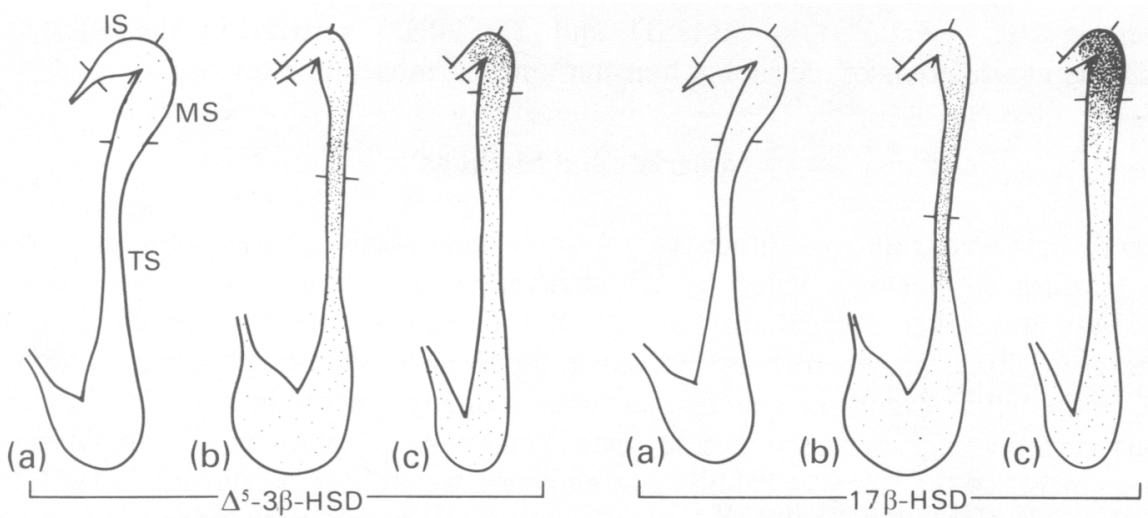

Text-fig. 1. Diagrammatic representation of the distribution and intensity of staining of $\Delta^{5}-3 \beta$ and 17ß-HSD activity in the excurrent ducts of (a) rabbit, (b) hamster and (c) marmoset monkey. The rabbit ducts show weak enzyme activity confined to tubules in the middle segment of the epididymis. The hamster and marmoset exhibit $3 \beta-\mathrm{HSD}$ activity which is maximal in the middle segment of the epididymis. $17 \beta$-HSD activity is also maximal in the middle segment of the epididymis in both species but the staining intensity in the marmoset is higher than that seen in the hamster. IS, initial segment; MS, middle segment; TS, terminal segment.

2 and 3). Formazan deposits were localized in the apical and basal cytoplasm of epithelial cells in tissues incubated with DHEA and testosterone. The luminal contents in the middle segment were lightly stained when both the steroid substrates were used. In the absence of phenanthroline inhibitor, staining was comparatively heavier (Pl. 1, Fig. 4) and was additionally present in the efferent ducts and terminal segment of the epididymis.

\section{Hamster}

In comparison with the ducts in the rabbit, those in the hamster displayed much more HSD activity as determined by the amount of formazan deposited. Staining was minimal in the efferent ducts and initial segment. An appreciable histochemical reaction for $\Delta^{s}-3 \beta$-HSD and 17 $\beta$-HSD was evident in the epithelium of the proximal-middle segment (Pl. 1, Figs 1, 5 and 6). This was intense in the distal-middle segment and gradually declined distally. As in the rabbit, formazan deposits occurred as discrete granules in the apical and basal cytoplasm of epithelial cells, but in most of the tubules in the terminal segment and vas deferens, the reaction product had a flocculent appearance (Pl. 2, Figs 7 and 8). The intensity of the stain obtained with DHEA as substrate was comparable to that seen after incubating sections with testosterone.

\section{Marmoset monkey}

Enzyme activity was present throughout the excurrent ducts in the marmoset. However, the intensity of stain for HSD varied considerably between animals, though there was a consistent pattern of distribution of the reaction product in different parts of the excurrent ducts. As in the hamster, enzyme activity was low in tubules in the efferent ducts and maximal in tubules in the middle segment, but the epithelium in tubules in the initial segment (Pl. 2, Figs 9 and 10) contained an appreciable amount of reaction product when both DHEA and testosterone were used as substrates. On the whole, the reaction with testosterone substrate was stronger than that obtained with DHEA. Formazan staining of the luminal contents was high in the middle and 
terminal (Pl. 2, Figs 11 and 12) segments. The epithelial reaction for HSD was slightly lower in the terminal segment (Pl. 2, Fig. 12) when compared with that seen in the middle segment.

The above findings on the distribution and intensity of staining of $\Delta^{5}-3 \beta-H S D$ and $17 \beta-H S D$ in the rabbit, hamster and marmoset monkey are summarized in Text-fig. 1.

\section{Discussion}

In the present study, alcohol dehydrogenase present in the excurrent duct epithelium was inhibited by phenanthroline, therefore formazan deposits represented only steroid dehydrogenase activity. Furthermore, since diaphorase activity, which is required for a normal histochemical reaction (Wattenburg, 1958), was shown to be present throughout the excurrent ducts, a lack of staining in some regions of the tract reflected a true absence of the hydroxysteroid dehydrogenase.

The rabbit ducts were characterized by an absence of enzyme activity except for low amounts seen in the epithelium and lumen of tubules in the middle segment. Killian \& Amann (1974), using DHEA and testosterone substrates, were unable to detect $\Delta^{5}-3 \beta-H S D$ or $17 \beta$-HSD activity in the epididymal epithelium in the single rabbit they tested. The luminal spermatozoa, however, effectively reduced testosterone, indicating the presence of $17 \beta-H S D$. These results are in agreement with those obtained from the biochemical studies of Frankel \& Eik-Nes (1970) who used rabbit epididymal slices in culture to demonstrate the conversion of labelled precursors to androgens. These workers inferred an absence of $\Delta^{5}-3 \beta$-HSD from the fact that $\left[4-{ }^{14} \mathrm{C}\right]$ dehydroepiandrosterone failed to be oxidized to androstenedione. [1,2$\left.{ }^{3} \mathrm{H}\right]$ Testosterone, on the other hand, was converted to androstenedione, indicating the presence of $17 \beta$-HSD. The above results must be viewed with caution in that in-vitro studies may not necessarily parallel the situation in-vivo.

The ability of the epididymis to synthesize steroids has been shown in a number of species including rat, mouse, hamster, rabbit and ram (Inano, Machino \& Tamaoki, 1969; Frankel \& Eik-Nes, 1970; Fawcett \& Hamilton, 1970; Hamilton, 1971). It is therefore surprising that the rabbit epididymis should possess such low quantities of histochemically demonstrable $\Delta^{5}-3 \beta-H S D$ and $17 \beta-H S D$ which are key enzymes in the steroidogenic pathway (Dorfman \&

\section{PLATE 1}

Fig. 1. Frozen section of the middle segment of the rabbit epididymis. The lumen contains spermatozoa. Haematoxylin \& eosin, $\times 264$.

Fig. 2. A corresponding frozen section to Fig. 1 pretreated with phenanthroline and incubated with DHEA substrate. Small amounts of formazan deposits occur as discrete granules in the epithelium, indicating weak $\Delta^{5}-3 \beta$-HSD activity. $\times 264$.

Fig. 3. Frozen section of the middle segment of the rabbit epididymis, pretreated with phenanthroline and incubated with testosterone substrate. The small number of granules in the epithelium of tubules represents weak $17 \beta$-HSD activity. $\times 264$.

Fig. 4. Frozen section of the middle segment of the rabbit epididymis incubated with DHEA substrate but not pretreated with phenanthroline. The greater epithelial reaction for $3 \beta$-HSD compared to that seen in Fig. 2 is due to non-specific staining. Formazan granules are also evident in the lumen. $\times 264$.

Fig. 5. Frozen section of the proximal-middle segment of the hamster epididymis showing cross-sections of tubule. Haematoxylin \& eosin, $\times 264$.

Fig. 6. Comparable frozen section to Fig. 5. The tissue was pretreated with phenanthroline. Sites of $17 \beta$-HSD activity are seen in the epithelium and lumen of the tubules. $\times 264$. 
PLATE 1
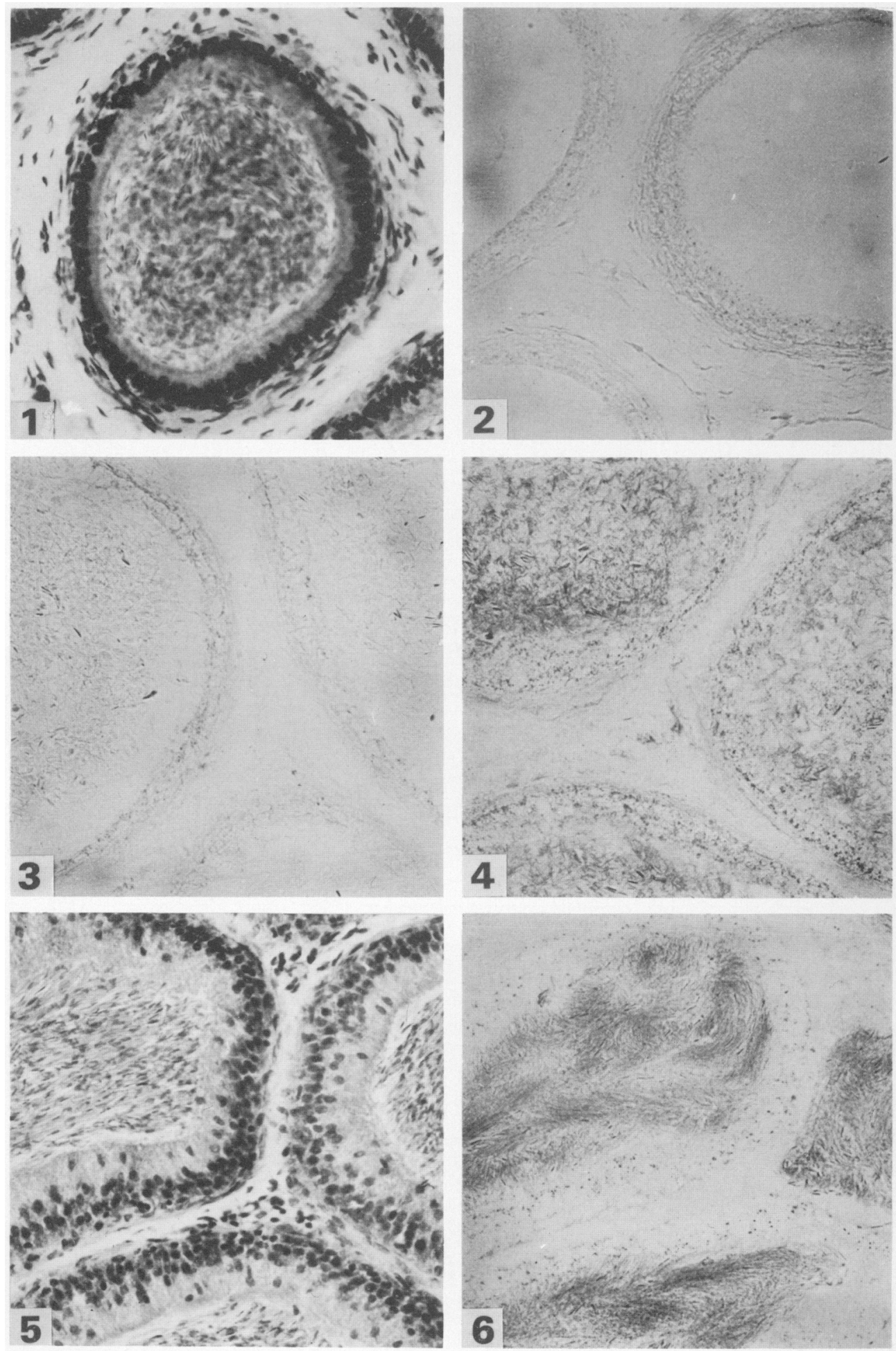

(Facing p. 98) 

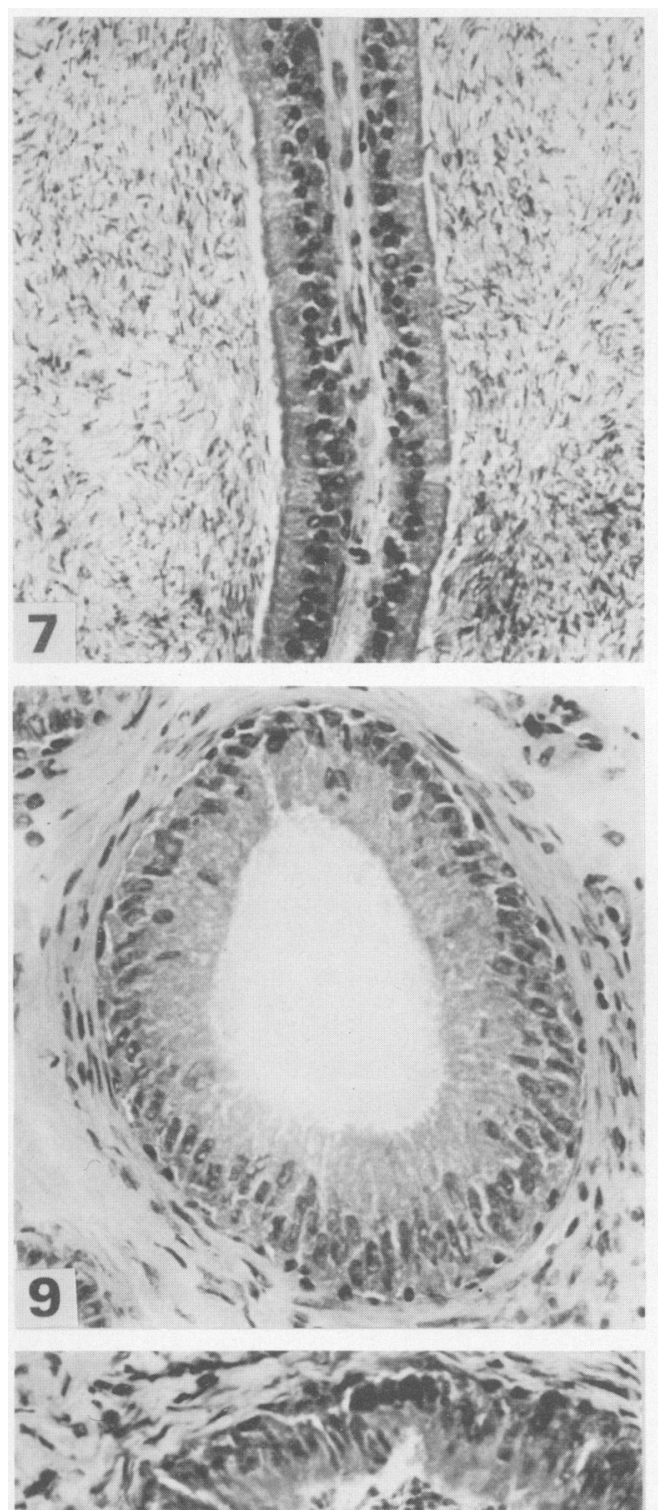

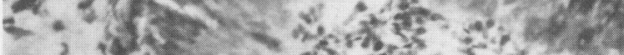

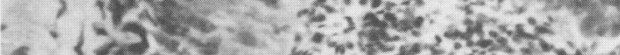

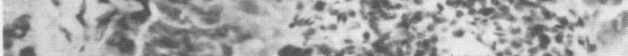

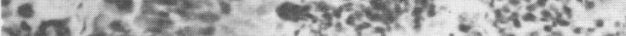

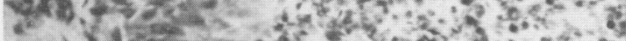

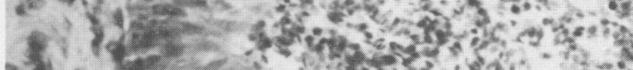

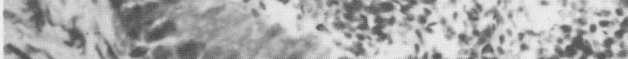

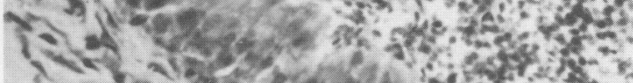

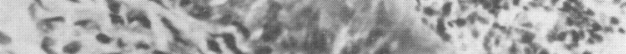

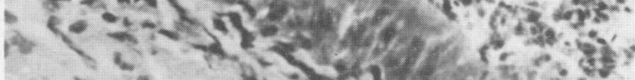
$11^{-2}-v_{1}+200$
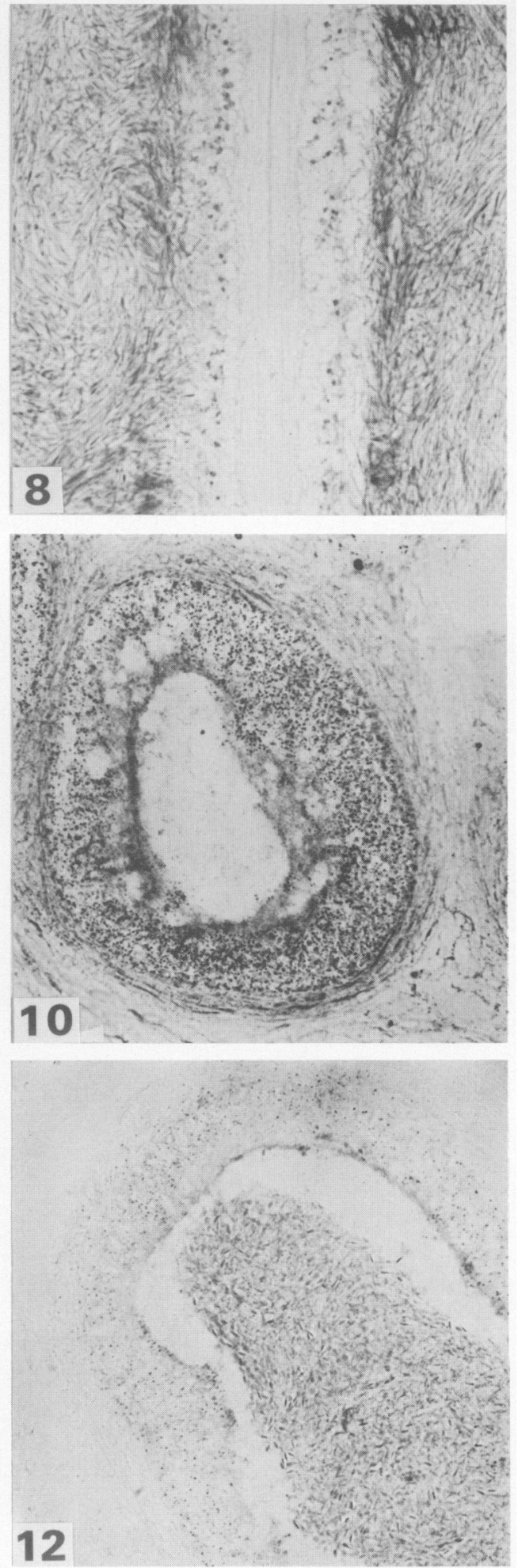
Ungar, 1965). An explanation for this discrepancy could be that these enzymes show stereospecificity with regard to their substrates (Baillie, Ferguson \& Hart, 1966).

The hamster and marmoset displayed more formazan reaction product in their excurrent ducts compared with the rabbit. The $\Delta^{5}-3 \beta$-HSD showed a similar staining intensity in both animals but $17 \beta$-HSD activity was more pronounced in the marmoset epididymis. As in the rabbit, HSD activity was found in the middle segment. These observations confirm the species specificity in the activity and distribution of $3 \beta$-HSD and $17 \beta-$ HSD respectively.

An important point emerging from these studies is that the region of maximal enzyme staining, i.e. the middle segment of the epididymis, corresponds to the region where spermatozoa first exhibit their fertilizing ability (rabbit: Bedford, 1966; Orgebin-Crist, 1967; hamster: Horan \& Bedford, 1972; Moore, 1981; marmoset: Moore, 1981). A similar conclusion has been drawn from histochemical studies on the localization of HSD in the epididymis of the hamster (McGadey et al., 1966) and rhesus monkey (Dinaker et al., 1977). The presence of hydroxysteroid dehydrogenase in the mammalian epididymis would provide a mechanism for the conversion of androgens to a number of steroid metabolites. The increase in enzyme activity in regions of the duct where spermatozoa first acquire their fertilizing ability suggests that these metabolites may be involved in sperm maturation.

\section{References}

Baillie, A.H., Ferguson, M.M. \& Hart, D.McK. (1966) Developments in Steroid Histochemistry. Academic Press, London.

Bedford, J.M. (1966) Development of the fertilizing ability of spermatozoa in the epididymis of the rabbit. J. Exp. Zool. 163, 319-329.

Chayen, L., Bitensky, L., Butcher, R.G. \& Poulter, L.W. (1969) A Guide to Practical Histochemistry. Oliver \& Boyd, Edinburgh.

Dinakar, N., Arora-Dinakar, R., Kumar, P., Talesara, C.L. \& Prasad, M.R.N. (1977) Histochemical localization of dehydrogenases in different regions of the epididymis of the adult rhesus monkey Macaca mulatta. J. exp. Biol. 15, 865-869.

Dorfman, R.I. \& Ungar, F. (1965) Metabolism of Steroid Hormones. Academic Press, New York.
Fawcett, D.W. \& Hamilton, D.W. (1970) Electron microscopic and biochemical evidence for steroid synthesis in the epididymis. In Morphological A spects of Andrology, pp. 119-121. Eds F. Holstein \& E. Horstmann. Grosse, Berlin.

Fawcett, D.W. \& Hoffer, A.P. (1979) Failure of exogenous androgen to prevent regression of the initial segments of the rat epididymis after efferent duct ligation or orchidectomy. Biol. Reprod. 20 , $162-181$.

Frankel, A.I. \& Eik-Nes, K.B. (1970) Metabolism of steroids in the rabbit epididymis. Endocrinology 87, $646-652$.

Glover, T.D. \& Nicander, L. (1971) Some aspects of structure and function in the mammalian epididymis. J. Reprod. Fert., Suppl. 13, 39-50.

\section{PLATE 2}

Fig. 7. Frozen section of the terminal segment of the hamster epididymis. Note the large lumen and narrow epithelium. Haematoxylin $\&$ eosin, $\times 264$.

Fig. 8. Comparable frozen section to Fig. 7. Reaction product, indicating $17 \beta$-HSD activity, has a flocculent appearance in contrast to the discretely granular appearance of formazan deposits seen in tubules in the middle segment (compare with Fig. 6). $\times 264$.

Fig. 9. Frozen section of the initial segment of the epididymis of the marmoset monkey. Sections of the lumen in this region are often devoid of spermatozoa. Haematoxylin \& eosin, $\times 264$.

Fig. 10. Corresponding frozen section to Fig. 9 pretreated with phenanthroline and incubated with testosterone. Dense epithelial reaction product indicates the presence of $17 \beta-H S D$ activity. $\times 264$.

Fig. 11. Frozen section of the terminal segment of the epididymis of the marmoset monkey. Spermatozoa are present in the lumen. Haematoxylin \& eosin, $\times 264$.

Fig. 12. Comparable frozen section to Fig. 11 showing the localization of 17ß-HSD. Considerably fewer formazan granules are seen in the epithelium compared to those present in tubules in the initial segment (see Fig. 10). $\times 264$. 
Hamilton, D.W. (1971) Steroid function in the mammalian epididymis. J. Reprod. Fert., Suppl. 13, 89-97.

Hamilton, D.W. (1975) Structure and function of the epithelium lining the ductuli efferentes, ductus epididymis, and ductus deferens in the rat. In Handbook of Physiology, Vol. V, Section 7, pp. 259-301. Eds D. W. Hamilton \& R. O. Greep. American Physiological Society, Washington, D.C.

Horan, A.H. \& Bedford, J.M. (1972) Development of the fertilizing ability of spermatozoa in the epididymis of the Syrian hamster. J. Reprod. Fert. 30, 417-423.

Inano, H., Machino, A. \& Tamaoki, B. (1969) In vitro metabolism of steroid hormones by cell-free homogenates of epididymides of adult rats. Endocrinology 84, 997-1003.

Killian, G.J. \& Amann, R.P. (1974) Detection of $3 \alpha-$, $3 \beta-$ and $17 \beta$-hydroxy-5$\beta$-steroid dehydrogenases in epididymal spermatozoa of Holstein bulls. J. Reprod. Fert. 38, 59-64.

McGadey, J., Baillie, A.H. \& Ferguson, M.M. (1966) Histochemical utilization of hydroxysteroids by the hamster epididymis. Histochemie 7, 211-217.

Moniem, K.A. (1972) Histochemical localization of $3 \beta$ hydroxysteroid dehydrogenases in the rat epididymis. J. Reprod. Fert. 28, 461-462.

Moore, H.D.M. (1981) An assessment of the fertilizing ability of spermatozoa in the epididymis of the marmoset monkey (Callithrix jacchus). Int. J. Androl. 4, 321-330.

Nicander, L. \& Plöen, L. (1979) Studies on regional fine structure and function in the rabbit epididymis. Int. J. Androl. 2, 463-481.

Orgebin-Crist, M.-C. (1967) Maturation of spermatozoa in the rabbit epididymis: fertilizing ability and embryonic mortality in does inseminated with epididymal spermatozoa. Annls Biol. anim. Biochim. Biophys. 7, 373-389.

Orgebin-Crist, M.-C., Danzo, B.J. \& Davies, J. (1975) Endocrine control of the development and maintenance of sperm fertilizing ability in the epididymis. In Handbook of Physiology, Vol. V, Section 7, pp. 319-338. Eds D. W. Hamilton \& R. O. Greep. American Physiological Society, Washington, D.C.

Rastogi, R.K., Saxena, P.K. \& Iela, L. (1976) Histochemical localization of some hydroxysteroid dehydrogenases in the mouse epididymis. In Hormone Research, pp. 44-48. Eds J. Girard \& M. Marois. S. Karger, Basel.

Sigman, D.S. (1967) Interactions of substrates, inhibitors and coenzymes at the active site of horse liver alcohol dehydrogenase. J. Biol. Chem. 242, 38153824.

Wattenburg, L.W. (1958) Microscopic histochemical demonstration of steroid $3 \beta$-ol dehydrogenase in tissue sections. J. Histochem. Cytochem. 6, 225-232. 